\title{
DIVERSIDAD NO ES LO MISMO QUE PLURALISMO: cambios en el campo religioso argentino (1985-2000) y lucha de los evangélicos por sus derechos religiosos
}

\author{
Alejandro Frigerio* \\ Hilario Wynarczyk ${ }^{* *}$
}

\begin{abstract}
Resumen: El trabajo argumentará que, para entender adecuadamente las modificaciones del campo religioso argentino, es necesario también incluir las resistencias sociales a esos cambios debido a las consecuencias que traen para la práctica y el desarrollo de las religiones minoritarias. A partir de aportes conceptuales de Beckford, el trabajo se propone distinguir diversidad de pluralismo religioso $\mathrm{y}$, atentos a la perspectiva de las "economías religiosas" propuesta por Stark y Iannaccone, se considerará al grado de regulación del mercado religioso como una variable de principal importancia para entender los cambios, tomando en cuenta tanto la acción gubernamental como la regulación social. Estas ideas se ejemplificarán examinando el aumento del movimiento social evangélico - más allá de su prioridad meramente religiosa - que lucha por derechos religiosos igualitarios en una situación de supuesto pluralismo religioso en Argentina.
\end{abstract}

Palabras clave: religión; pluralismo religioso; evangélicos; Argentina.

Para entender las modificaciones del campo religioso argentino es necesario también incluir las resistencias sociales a esos

\footnotetext{
* Profesor de la Maestría en Antropología Social de la Facultad Latinoamericana de Ciencias Sociales (Flacso) Buenos Aires e Investigador del Consejo Nacional de Investigaciones Científicas y Técnicas (Conicet). E-mail: alejandrofrigerio@gmail.com

** Profesor de la Universidad Nacional de General San Martín, Escuela de Posgrado y Escuela de Economía y Negocios. E-mail: hilariowynarczyk@yahoo.com.ar
}

Artigo recebido em 28 mar. 2008 e aprovado em 6 jun. 2008. 
cambios, porque traen consecuencias importantes para el desarrollo y la práctica de las religiones minoritarias. Las versiones usualmente aceptadas de la quiebra del monopolio religioso y la consiguiente instalación de un "pluralismo" o de un "mercado" religioso suponen una transición demasiado sencilla entre una situación y la otra e ignoran las dificultades que los grupos minoritarios continúan enfrentando en su accionar cotidiano. Estas interpretaciones están demasiado centradas en la relación del Estado con la Iglesia y por ende se focalizan sola o principalmente en la regulación gubernamental.

A partir de aportes conceptuales de Beckford, nos proponemos, en este trabajo, distinguir la efectiva existencia de "diversidad" de la de "pluralismo" religioso (que implica la valoración efectiva de esta diversidad). Tomando en cuenta contribuciones de la perspectiva de las "economías religiosas" propuesta por Stark, Finke e Iannaccone en diversas publicaciones, consideraremos el grado de regulación del mercado religioso como una variable de principal importancia para entender los cambios. Seguiremos la propuesta de Grim y Finke (2006) de tomar en consideración dimensiones de su regulación que exceden el marco puramente legal e incluiremos variables como la estigmatización de las nuevas religiones por los medios de comunicación y los esfuerzos de activistas anti-sectas por crear un contramovimiento social para oponérseles. La historia reciente de los dos principales grupos religiosos minoritarios, los evangélicos y los umbandistas, revela, además de lógicos intentos por procurar fieles, importantes esfuerzos en la esfera pública para sobreponerse a los distintos tipos de regulaciones, estatales y sociales (Frigerio, 2002, 2003; Wynarczyk, 2003b, 2006, 2007).

En este trabajo centraremos nuestra atención en los esfuerzos de los evangélicos, la primera minoría religiosa, por superar los intentos de regulación de sus actividades, tanto por parte del gobierno como de distintos sectores sociales. Todos estos emprendimientos ocurren en un contexto democrático, de vigencia de un mercado religioso y 
de supuesto pluralismo, mostrando que la transición de una situación de monopolio a una de mercado abierto no es tan unilineal ni ambos términos constituyen escenarios estancos, radicalmente diferentes. Un análisis más integral del cambio religioso en Argentina muestra, a su vez, la variedad de actores sociales involucrados y revela la necesidad de tomar en cuenta la fuerte injerencia tanto de actores religiosos como de actores seculares.

En la primera parte del trabajo presentaremos la perspectiva dominante del monopolio religioso católico (que creemos está vigente en buena parte de Latinoamérica) y pondremos en duda los presupuestos teóricos en los que se basa. Luego utilizaremos los aportes conceptuales de Beckford (2003) y de Grim y Finke (2006) para proponer una perspectiva algo más multidimensional del control de los comportamientos religiosos, que incluya su regulación extra-estatal. Finalmente, describiremos cómo los evangélicos desarrollaron, a partir de un movimiento social religioso focalizado en la conversión de creyentes, un movimiento social que pugna por superar una situación de injusticia y obtener iguales derechos religiosos en un estado de verdadero pluralismo religioso.

\section{Monopolio, diversidad y pluralismo religioso}

En un trabajo anterior (Frigerio, 2007), utilizando datos derivados del caso argentino, proponíamos la necesidad de repensar el rol del catolicismo dentro del campo religioso latinoamericano. Argumentamos que, para evaluar más adecuadamente el tipo de influencia que ejerce dentro de éste, era necesario, en primer lugar, reconsiderar el concepto de "monopolio religioso" y examinar más finamente sus distintos efectos sobre variables que a menudo son consideradas coextensivas: creencias, identidad y, especialmente, legitimidad. Sugerimos que el monopolio católico era más sobre las creencias religiosas socialmente legítimas que sobre las creencias 
religiosas en general, y que el predominio de una identidad social católica no implicaba, necesariamente, la reivindicación de identidades personales ni colectivas católicas (Frigerio, 2007). En segundolugar, considerábamos necesario debatir la utilización ubicua y acrítica en nuestra región del paradigma bergeriano de la religión en general y del catolicismo en particular, como un "dosel sagrado". Para ello, tomábamos en cuenta las críticas de Beckford (2003) a esta posición y utilizábamos también algunas proposiciones derivadas del paradigma norteamericano de la elección racional, particularmente las que se refieren a la naturaleza de los monopolios religiosos y al proceso de secularización. Utilizando básicamente los mismos autores, ahora argumentaremos que, junto con la reconsideración del concepto de "monopolio", es necesario también repensar otros conceptos como los de "mercado religioso", "diversidad" y "pluralismo", que se piensa constituyen su contracara.

Según una perspectiva que parece gozar de consenso en nuestra región, la quiebra del "monopolio católico" llevaría a una situación de pluralismo y a un mercado de bienes simbólicos de salvación, en el que cada individuo ya no sería "cautivo" de la oferta eclesial y buscaría nuevas creencias e identidades entre las nuevas ofertas - o armaría su propia síntesis, en un proceso cada vez más acentuado de individuación de las creencias. Esta transición de una situación a otra generalmente es postulada pero no suficientemente problematizada ni descripta.

Algunos ejemplos referidos al caso argentino:

A partir de la pluralización del mercado religioso se puede observar una fuerte reestructuración del campo religioso: la pérdida del monopolio de la Iglesia Católica en la producción y distribución de los bienes de salvación en el marco de una sociedad cada vez más heterogénea y con identidades menos totalizadoras. [...] Las distintas formas de religiosidad que hoy encontramos expresan vías alternativas de agrupamiento y de sociabilidad, ante la crisis de aquellas instituciones totalizantes antaño dadoras de sentido, ante 
la incertidumbre y el quiebre de certezas constatable en el mundo actual [...] (Giménez Beliveau y Esquivel, 1996, p. 117-118).

Las principales instituciones históricas que habían dado sentido a los argentinos durante el origen, desarrollo y apogeo del Estado de Bienestar (de los años 20 a los 70s) habían sido: el propio Estado... especialmente en lo referido a educación, salud, trabajo y transportes, las Fuerzas Armadas y la Iglesia Católica consideradas [...] como las fundadoras y garantes de la argentinidad y dadoras de identidad integradoras y totalizadoras, los sindicatos y los partidos políticos [...] Hoy estas instituciones formadoras de imaginarios múltiples aparecen cuestionadas, desacreditadas y perdiendo legitimidad en el conjunto de la población. [...] Por lo tanto hoy se da el siguiente proceso: los barrios y periferias de las ciudades se están transformando en un ACTIVO MERCADO RELIGIOSO con ofertas y demandas diferenciadas. Lo nuevo al fin del milenio es que el antiguo monopolio religioso católico en sectores populares se está quebrando... [...] Los sectores populares están buscando felicidades - bienes simbólicos de salvación - en identidades religiosas alternativas a la oficial e institucional. Por otro lado esto significa que cada vez es menor la clientela religiosa cautiva. [...] $\mathrm{El}$ actual surgimiento de nuevas creencias en Argentina nos remite a un mercado de bienes simbólicos que puso fin al antiguo monopolio católico en sectores populares [su énfasis] (Mallimaci, 2001, p. 22-24).

Lejos de ser una visión meramente local, esta perspectiva es compartida en mayoro menormedida por buena parte de los estudiosos latinoamericanos hispanoparlantes, ya que se deriva de una visión mayor sobre las relaciones entre religión y modernidad propuesta por autores de gran predicamento en la región - especialmente Peter Berger y Danièle Hervieu-Léger - citas prácticamente obligadas al brindar un panorama de la situación actual de la religión. Para comprobarlo, basta comparar los marcos teóricos de tres importantes estudios cuantitativos sobre las creencias contemporáneas realizados en la ciudad de Montevideo, Uruguay (Da Costa, 2003, p. 5-37); en la de Guadalajara, México (Fortuny, 1999, p. 17-29); y en el partido de Quilmes, en el Gran Buenos Aires en Argentina (Esquivel, 
Hadida y Houdin, 2001, p. 33-38; Mallimaci, 2001, p. 17-24). En estos estudios, luego de las críticas a la visión sociológica clásica sobre la secularización que acompañaría a la vida moderna, con la consiguiente pérdida de importancia o desaparición de la religión, son reiteradas las citas a los trabajos de Hervieu-Léger, según los cuales la secularización sería "no la pérdida de la religión en una sociedad globalmente racionalizada, sino una reorganización general de las formas de religiosidad" (1998, p. 20). La diversificación religiosa, la individuación de la creencia y la quiebra de la memoria colectiva serían rasgos principales de esta reorganización de la religión. Esta perspectiva resalta la continuada importancia de la religión, pero acentúa (al menos en su versión local) una situación de "antes" y "después" que, brindando una versión algo estereotípica del pasado monopolizado por el catolicismo, singulariza en demasía lo novedoso de la dinámica religiosa actual en una situación de "pluralismo".

Como soporte teórico subyacente a estas ideas se puede reconocer la visión de Peter Berger de la religión como un "dosel sagrado" y su posición acerca de cuáles son las consecuencias que el pasaje de una situación de monopolio para una de pluralismo religioso tiene para las creencias y las identidades religiosas. Esta idea del "dosel sagrado" ha sido objeto de crítica en los últimos años, especialmente por los sociólogos norteamericanos Rodney Stark, Roger Finke y Laurence Iannaccone, principales propulsores del paradigma de la elección racional, así como por el sociólogo inglés James Beckford, quien en su último libro Social Theory and Religion (2003) realiza un fuerte cuestionamiento a las ideas de Berger.

Como parte de su rediscusión del concepto de pluralismo religioso, Beckford señala que la concepción tradicional del término ha sido influenciada, en gran medida, por los "escritos casi canónicos" de Berger y Thomas Luckmann. Concentrándose principalmente en los trabajos del primer autor, sostiene que "el punto de partida de 
Berger, la afirmación según la cual 'a través de la mayor parte de la historia humana los establishments religiosos han existido como monopolios en la sociedad (1969, p. 134)' es, como mucho, una afirmación debatible, y probablemente, equivocada" (2003, p. 82).

Según el sociólogo británico:

Parece difícil afirmar que el monopolio religioso alguna vez significó la total ausencia de diversidad religiosa [...] Así, el contraste de Berger entre "tradición" y "modernidad" es exagerado. [...] (Esta visión) ignora el hecho de que los sentimientos y las creencias religiosas casi siempre han sido diversas y menosprecia la fuerza y el esfuerzo que ha debido hacerse para mantener la ficción de un mundo unitario de verdad religiosa" (Beckford, 2003, p. 83).

Desde su perspectiva, los conflictos entre visiones del mundo que se ven al comienzo de la modernidad

[...] reflejan más una disminución en la capacidad de los que tenían poder para suprimir disidencia que una pérdida de fe en una única fuente de verdad. Las preguntas sociológicas interesantes no versan sobre la credibilidad de algún tipo de aserción religiosa de verdad sino sobre las condiciones sociales que permitieron que una variedad de creencias, prácticas y organizaciones adquirieran aceptación, permiso o legitimidad. El acento debería estar sobre el poder y la violencia más que en la supuesta pérdida o disminución del monopolio sobre la verdad y el surgimiento del relativismo filosófico [nuestro énfasis] (Beckford, 2003, p. 83-84).

Para este estudioso, por lo tanto, lo que se resquebrajaría sería no tanto la credibilidad de la religión sino la diferencial legitimidad de distintas creencias religiosas a lo largo del tiempo. Sus ideas traen, entonces, al centro del análisis el tema del poder y de la legitimidad social - de algún(os) grupo(s) religioso(s) frente a otros. En el mismo libro, Beckford cuestiona también la fácil identificación que se realiza entre diversidad y pluralismo religioso. Para él, bajo el concepto pluralismo se suelen confundir tres aspectos diferentes de la religión en la vida pública: la magnitud de la diversidad religiosa, el grado en 
que los distintos grupos religiosos existentes son aceptados en una sociedad y el apoyo por el valor moral o político de la diversidad religiosa. Reserva el término pluralismo para esta última acepción, es decir no sólo para la mera existencia de diversidad religiosa, sino su efectiva valoración (Beckford, 2003, p.74).

En otra argumentación con muchos puntos en común con esta posición, desde la perspectiva de la elección racional, se afirma que es el pluralismo y no el monopolio religioso el estado natural de las economías religiosas, ya que una sola firma religiosa difícilmente podrá atender a un mercado originalmente segmentado de consumidores religiosos. Según quienes adhieren a esta perspectiva, no hay religiones efectivamente monopólicas, sino mercados regulados (Stark e Iannaccone, 1993; Frigerio, 2000a). Por lo tanto, el grado de regulación del mercado se convierte así en una de las variables principales para entender los cambios religiosos - lo que vuelve a traer el tema del poder al centro del análisis. En un artículo reciente, Grim y Finke (2006) proponen que para examinar adecuadamente el grado de regulación de un mercado religioso es necesario ir más allá de la habitual preocupación por la regulación estatal y considerar también el favoritismo estatal, así como la regulación social. Según estos autores, la regulación gubernamental consiste en "las restricciones que sufre la práctica o la elección de una religión a causa en las leyes oficiales, las políticas o las acciones administrativas del Estado". Esta forma de regulación no se limita a las normas legales sino que también incluye restricciones administrativas que pueden limitar o perjudicar las acciones de determinados grupos. Cuando las acciones del Estado benefician sólo a determinada religión o religiones existiría una situación de favoritismo estatal. Esta sería "la existencia de subsidios, privilegios, apoyo o sanciones favorables del Estado a una religión o a un pequeño grupo de ellas". Aquí encontramos desde los más obvios privilegios constitucionales, subsidios financieros hasta acciones parciales de funcionarios administrativos, acceso 
de sólo algunos tipos de sacerdotes a distintos contextos, subsidios a escuelas, etc. Por último, la forma menos estudiada de control porque excede el ámbito estatal y puede manifestarse de múltiples y menos obvias (elusivas) maneras es la regulación social. Para estos autores, incluiría "las restricciones que sufre la práctica o la elección de una religión a causa de las acciones de otros grupos religiosos, asociaciones o debido al contexto cultural". Puede ir desde la asignación de status desviante a determinadas creencias o prácticas religiosas hasta la persecución de determinadas religiones por grupos más o menos organizados.

Aunque enunciadas por autores diferentes, estas posiciones tienen elementos en común que, tomados en cuenta, nos llevarían a reconsiderar la situación actual de "pluralismo" de muchos de nuestros países. Concuerdan en la necesidad de cuestionar el monopolio como el estado natural de la religión en la sociedad y enfatizan el esfuerzo de regulación que se realiza, tanto desde el Estado como desde otras instituciones sociales o desde el propio contexto cultural, para sostener este monopolio que nunca es completo. Para ellos, el crecimiento de la diversidad no significa pluralismo (que sería su valoración) y en vez de suponer un tránsito casi necesario y poco problemático del "monopolio" al pluralismo consideran que es interesante ver los grados de regulación que existen en distintos momentos. Para ello, es necesario reconocer que esta regulación se expresa a través de diversas dimensiones que exceden a las iniciativas estatales.

La importancia de la regulación religiosa extralegal se puede apreciar para el caso argentino en el hecho de que, a pesar de que la legislación referida a la libertad religiosa casi no cambió en los últimos veinte años, buena parte de los esfuerzos realizados en espacios públicos por las dos más importantes minorías religiosas (evangélicos y umbandistas) fueron con el motivo de mejorar su imagen en los medios de comunicación donde eran fuertemente 
estigmatizados; por protestar contra el creciente control burocrático sobre sus templos debido a modificaciones administrativas en el Registro de Cultos; o para movilizarse contra nuevos proyectos de ley religiosa presentados por distintos legisladores y funcionarios en el parlamento nacional. A continuación, examinaremos, entonces, el desarrollo de un movimiento social evangélico en lucha contra la regulación estatal y social de sus actividades y derechos civiles.

\section{Los evangélicos contra la regulación estatal y social}

El campo evangélico, usualmente presentado como un colectivo homogéneo que admitiría ser considerado como "el movimiento evangélico argentino" (Maróstica, 1997), es en realidad un conjunto de iglesias y organizaciones atravesado por tensiones internas propias de un campo de fuerzas.

Según el análisis de Wynarczyk (2007), este campo es reductible a un sistema binario, donde una de las partes, en virtud de su capital demográfico y capacidad organizadora para la movilización colectiva, juega un papel predominante. Este autor distingue un polo conservador bíblico que proyecta su utopía como "esperanza escatológica" en el plano sobrenatural mientras relega "el mundo" a una posición de segundo orden ${ }^{2}$. Señala, además, la existencia de un polo histórico liberacionista, que proyecta la esperanza cristiana en la historia construida por los hombres aquí "en el mundo", en el cual identifica las estructuras de opresión, entendidas desde una perspectiva asistida por el instrumental de la teología de la liberación como el sitio del mal. Lo fundamental en relación a la dinámica del campo como totalidad es que las fuerzas en determinados momentos se unen y en otros compiten por el predominio interno y tienden a imponer su teología y su marco interpretativo de la realidad social (Wynarczyk, 2007). 
En la década del 90 los evangélicos conservadores bíblicos (muchas veces registrados con insuficiente precisión como "fundamentalistas", sin recalcar que los fundamentalistas son únicamente un fragmento de los conservadores bíblicos) protagonizaron una entrada en la escena pública de la sociedad civil argentina en dos terrenos: 1) la protesta por la "igualdad de cultos" y 2) la formación de partidos políticos ${ }^{4}$.

Los conservadores bíblicos que llevaron adelante el proceso cívico de reclamo y protesta frente a la conculcación de sus derechos eran los herederos de una cosmovisión radicalmente ascética que asociaba la política con el mundo como la zona del mal (Wynarczyk, 2005). A partir de esa constatación no era de esperar de ellos una movilización social de ese tipo. Pero, en cierto momento de su historia, comenzaron a preocuparse por ingresar en la arena de batalla jurídica. Y pusieron de manifiesto su capacidad para utilizar las retóricas y técnicas de acción colectiva adecuadas. Podían usar las herramientas del "mundo", aunque al servicio del Reino, que no sería de este "mundo". Así, un movimiento social de tipo religioso (movimiento social en lato sensu) pasó a protagonizar acciones propias de un movimiento social en sentido estricto, de actores colectivos que pretendían denunciar una injusticia y defender sus intereses negados, tanto en las sedes del Poder Legislativo y Ejecutivo de la nación, como en los medios de comunicación y en las calles de la Ciudad Autónoma de Buenos Aires, la Capital Federal del país ${ }^{5}$.

\section{a) La movilización religiosa de los evangélicos}

En 1954 tuvo lugar un primer auge evangélico facilitado por la predisposición del presidente Juan Domingo Perón que hizo posible la campaña multitudinaria de predicación y milagros de sanidad del evangelista texano Tommy Hicks, con quien se fotografió con uniforme militar de gala. La entrada de las iglesias evangélicas en la agenda de Perón, que estaba en serio conflicto con la Iglesia 
Católica, alimentó una tensión interna del campo evangélico de fuerzas. Los evangélicos que sostenían la separación de la iglesia y el Estado encontraban puntos de afinidad con la agenda política del socialismo y el liberalismo y eran antiperonistas; por otro lado, algunos pentecostales desarrollaban estrategias de transacciones prebendarias con el Estado.

El curso histórico de los acontecimientos no tuvo consecuencias relevantes como sucedió luego en la década del 80 ya que por entonces el sector pentecostal no era demasiado fuerte y porque la apertura gubernamental hacia otros credos religiosos fue limitada en el tiempo - duró desde que Perón se enemistó con la Iglesia Católica hasta su derrocamiento, aproximadamente entre 1950 y 1955. Por otro lado, la regulación social contra grupos no católicos se mantuvo, como muestra la oposición que tuvieron que enfrentar los pastores evangélicos por parte de colegios médicos de las distintas ciudades en las que realizaban sus campañas de sanación y salvación ${ }^{6}$. Pese a contar con el beneplácito presidencial, los propios organizadores de las campañas de Tommy Hicks debieron superar la oposición de las asociaciones médicas (Saracco, 1989, p. 211) 7 .

Tras la caída de Perón en 1955 continuaron vigentes las restricciones a los movimientos religiosos debido a la casi continua presencia de gobiernos militares asociados con la Iglesia Católica y a la gran conflictividad social vinculada a la proscripción política de los sectores populares vertebrados de diferentes maneras en el peronismo $^{8}$. En 1978 la dictadura militar de Videla sancionó una ley que reforzó la regulación del mercado religioso. Esta ley 21.745 reinstaura el Registro Nacional de Cultos (creado al comienzo del gobierno peronista en 1946), ahora con el propósito de "supervisar" y "establecer un control efectivo" sobre los cultos no católicos, según reza su introducción (Secretaría de Culto, 2001, p. 160). Todas las agrupaciones religiosas distintas de la Iglesia Católica Apostólica Romana debían registrarse y proveer información sobre su doctrina, 
rituales, organización, historia y los nombres de sus autoridades locales e internacionales, entre otros ítems ${ }^{9}$.

Durante la década de 1970 la división binaria del campo evangélico de fuerzas reflejó la división del campo político internacional en la Guerra Fría. En este período cada polo expresaba frente al "mundo" una posición basada en una hermenéutica bíblica, pero también en sus relaciones fraternales con iglesias y federaciones de iglesias de otros países. Las iglesias del polo conservador bíblico ya se hallaban ubicadas en la posición demográfica predominante dentro del campo. En ese lapso adoptaron una postura de evasionismo político afín con la cosmovisión dualista que radicaliza la separación entre el "mundo" y el "cielo". Las iglesias del polo histórico liberacionista, en cambio, se tornaron demográficamente inertes. Sin embargo, acumularon un mayor capital de prestigio intelectual y reconocimiento moral hacia las posiciones que asumieron frente a la pobreza y los Derechos Humanos.

En ese escenario, desde comienzos de la década del 80 tuvo lugar el desencadenamiento de un ciclo de movilización colectiva de tipo religioso protagonizado por el polo conservador bíblico y el subsector neopentecostal instalado de hecho como "locomotora" del proceso. La vuelta de la democracia en 1983 con la presidencia de Raúl Alfonsín del partido Unión Cívica Radical, luego del cierre de la violenta dictadura militar que azotó al país desde 1976 hasta la retirada de Malvinas, permitió diversas muestras públicas de conductas que en el contexto anterior hubieran sido consideradas desviantes y reprimidas. La primavera democrática hizo posible una nueva etapa de activismo religioso en carpas, cines convertidos en iglesias y de campañas en estadios ubicados dentro de la ciudad de Buenos Aires. Esto otorgó una alta visibilidad a las actividades de "los evangelistas" como los medios comenzaron a denominarlos en varias notas en revistas y diarios que constataban con algo de sorpresa esta inesperada presencia (Frigerio, 1993). Todo esto sucedió sin que 
perdiera vigencia la ley de culto de la dictadura militar que establecía la necesidad de registro de todos los cultos no católicos. De hecho, durante la década de 1980 hubo un gran crecimiento en la cantidad de agrupaciones que se registraron (principalmente pentecostales y umbandistas), aunque no es posible afirmar si eran todos grupos religiosos nuevos o que ya funcionaban con anterioridad y ahora querían regularizar su situación.

La "visitación del Espíritu Santo" a la Argentina (término émico del colectivo evangélico movilizado para "conquistar la Argentina para Cristo") constituyó desde los 80 la creencia generalizada básica, el dínamo de la acción proselitista y el marco integrador de otras creencias. Desde los 90 comenzó a difundirse el concepto de iglesia apostolar con líderes ungidos que predican un evangelio de poder espiritual. El poder dentro del campo evangélico debía pasar de las denominaciones a las iglesias apostólicas y esto creó nuevamente tensiones que afectaron internamente al polo conservador bíblico. Pero el nuevo concepto siguió impulsando un siempre exitoso reclutamiento de adeptos.

\section{b) Alcance de masa crítica}

A rigor no existen informaciones exhaustivas y científicas sobre la distribución religiosa de la población argentina. Luego de 1960 los censos nacionales no registran esta clase de información. Todas las estimaciones que manejamos están construidas sobre la yuxtaposición de datos provenientes de estudios parciales de origen privado. Algunos producen una mala discriminación de las variables debido al desconocimiento de la taxonomía eclesiástica del campo evangélico. En ese encuadre de cantidad y calidad de los datos, contrastados con la experiencia impresionista pero muy rica de los pastores evangélicos (y algunas informaciones provistas por sacerdotes católicos), establecemos las siguientes consideraciones.

La población de evangélicos había evolucionado desde el $0.7 \%$ (censo 1895, población del país 4.044.911, evangélicos 
estimados 28.314) al 2\% (censo 1947, población 15.893.827, evangélicos estimados 317.876 ) y el $2.6 \%$ (censo 1960, población 20.013.793, evangélicos estimados 520.358). En las décadas del 60 y el 70, marcadas por un mayor control del mercado religioso, a rigor no sabemos qué sucedió. En los 90 las mediciones existentes comienzan a verificar que el campo evangélico alcanzó un umbral del 9\% a nivel nacional. Luego permiten estimar que en la década del 2000 podría encontrarse en el orden del $10 \%$ al $13 \%{ }^{10}$.

Los evangélicos actualmente (2008) podrían superar los 3.5 millones de habitantes según la estimación más conservadora, y aproximarse a los 5 millones, tal vez. Además los datos deben ser ajustados de acuerdo con fluctuaciones asociadas a los niveles socioeconómicos. Datos de algunos estudios enfocados en el Conurbano Bonaerense (Esquivel, Hadida y Houdin, 2001) y la Capital Federal (Wynarczyk y Johns, 1996) indican que el porcentaje de evangélicos en sectores populares urbanos puede alcanzar y superar el $20 \%$ de la población. En sectores medios y medios-altos podría hallarse entre el 3\% y el 5\%. En otro orden, las iglesias evangélicas superaban, a comienzos del 2000, el 75\% del total de las inscripciones en el Registro Nacional de Cultos y, en el 2007, podrían encontrarse por encima del 80\%. La mayor parte de estas inscripciones corresponden a iglesias localizadas en el Área Metropolitana formada por la Ciudad Autónoma de Buenos Aires (Capital Federal) y el Conurbano Bonaerense, la misma que concentra, a su vez, el 32\% de la población argentina según el censo de $2001^{11}$.

\section{c) Reacción social ante el crecimiento evangélico}

La visibilidad de los grupos religiosos no católicos, que, como vimos, comenzó con el retorno de la democracia al país en 1983, se hizo más evidente durante1985 y 1986, años en que varios grupos realizaron concentraciones multitudinarias y aumentaron su presencia en los medios. Este fue el caso de los evangélicos, 
quienes realizaron concentraciones masivas en la ciudad con pastores provenientes de Estados Unidos, como Luis Palau y Jimmy Swaggart, transmitieron programas de TV (generalmente americanos, como el Club 700, o el del propio Swaggart) y de radio, de pastores argentinos. Otros grupos también ganaron notoriedad. Los Testigos de Jehová, por ejemplo, llenaron en 1986 el mayor estadio de Buenos Aires y los de las ciudades de Rosario y Córdoba. Esta mayor presencia pública de grupos religiosos no tradicionales realizando grandes concentraciones en lugares inusuales (estadios de fútbol, cines, plazas) no pasó inadvertida. Durante 1986, varias de las principales revistas y diarios demostraron su preocupación o extrañeza por estas nuevas prácticas, dedicándoles su tapa y extensas notas. La asamblea plenaria de la Conferencia Episcopal Argentina se refirió al tema, señalando el inconveniente pastoral que representaba la "proliferación" de las sectas, atribuyéndolo a "cierto permisivismo en el control estatal y a la amplia campaña que sus cultores realizan a través de los medios" ${ }^{\prime 2}$. En octubre del mismo año, apareció el libro del periodista Alfredo Silleta "Las sectas invaden la Argentina", que se convirtió en un best-seller y tornó a su autor en el principal "especialista en sectas" en el país, figura ubicua en los próximos años en las notas en distintos medios acerca de las razones y consecuencias de este nuevo fenómeno.

Frigerio (1993) señala que durante el período de 1985 a 1995, aproximadamente, se pueden distinguir dos modelos de lo que serían y cómo funcionarían las "sectas". En el primer modelo, que predomina desde 1985 hasta 1988, aproximadamente, las sectas fueron visualizadas principalmente como grupos financiados desde el exterior que, con propósitos comerciales y/o desmovilizadores en lo político, captaban gente ignorante, de nivel socioeconómico bajo y con problemas sociales de distinta índole. Esta caracterización reflejaba el modelo prevalente en sectores de izquierda fuertemente influenciados por la teoría de la dependencia (tanto de la Iglesia Católica como de partidos políticos) acerca de las sectas como "una 
avanzada cultural del imperialismo" - de allí su dinero para alquilar estadios, cines, emitir programas de televisión, etc.

A partir de 1989, comenzó a imponerse otro modelo de qué son y cómo funcionan las "sectas" - derivado principalmente del movimiento anticultos norteamericano - según el cual éstas serían grupos que captan, mediante el "lavado de cerebro", a jóvenes insatisfechos con la sociedad o con problemas familiares y personales. Este nuevo marco interpretativo le daba una agregación de valor a su discurso en términos de un factor, la "peligrosidad": sectas capaces de ejercer manipulación psicológica, privar de la libertad y separar hijos de sus familias.

En el establecimiento de las sectas como un problema social y en la redefinición de sus características principales, cumplen un rol fundamental los grupos anti-sectas que se consolidaron en 19901991. Estos grupos opositores a los nuevos movimientos religiosos pero que se presentaban socialmente como dedicados al "estudio de las sectas" llegaron a monopolizar la interpretación del fenómeno en los medios, desplazando a los sacerdotes como principales fuentes consultadas. Se produjo, entonces, una secularización y a la vez una medicalización creciente del discurso, en la medida en que el avance de las sectas devendría un problema de salud mental por las consecuencias que la participación en ellas tendría para sus miembros ${ }^{13}$.

Aunque en esta época los pentecostales ya no eran considerados el modelo emblemático de secta (este honor lo tenían grupos minoritarios como Los Niños de Dios, y más tarde las religiones afro-brasileñas), las sospechas y la estigmatización los alcanzaban de todas maneras y las restricciones legales que se estaban pidiendo para las prácticas "sectarias" (prácticamente cualquiera no católica o protestante histórica) sin duda los alcanzarían también.

Esta reacción se puede conceptualizar como un verdadero contramovimiento social que intentó diversas estrategias para 
controlar o suprimir este nuevo desarrollo religioso. A través de la publicación de libros denunciando este problema social, de una intensa campaña de denuncias en los medios de comunicación y de lobby entre legisladores buscando apoyo para proyectos de ley religiosa más represivos, se intentaba influir sobre el Estado y movilizar a la población en general en contra de este "preocupante" fenómeno.

\section{d) Intentos de regulación en el ámbito del Estado}

Cuando, a comienzos de la década del 90, la creciente inquietud social por "el problema de las sectas" se transformó en un pánico moral (Frigerio y Oro, 1998), hubo intentos, en el ámbito del Poder Legislativo Nacional, de desarrollar proyectos de control más estricto sobre las "sectas" que alcanzarían a toda actividad religiosa no católica (aunque hubo grupos católicos acusados de ser "sectas dentro de la Iglesia"). Pero fue en la Secretaría de Culto (dependiente del Poder Ejecutivo Nacional) donde adquirió impulso el trabajo sobre un proyecto de ley de culto, conocido como el proyecto Centeno durante la gestión a cargo de católicos liberales que mantenían un grado importante de proximidad con la Unión Cívica Radical. La finalidad era reemplazar la ley de la dictadura militar en 1978, cuyas afinidades eran notorias con el espíritu de la legislación existente durante la primera presidencia de Perón.

Las principales confederaciones del polo conservador bíblico fueron consultadas desde 1991 por la Secretaría de Culto. Ese dato confirma la importancia que ya había alcanzado el polo conservador bíblico como una fuerza del campo religioso argentino. En un primer momento los dirigentes evangélicos consultados estuvieron a favor del proyecto Centeno ya que algunos legisladores nacionales habían presentado anteproyectos de ley mucho más restrictivos. Pronto, sin embargo, se puso de manifiesto la existencia de diferentes perspectivas en relación con la piedra angular de la discordia, el 
artículo 2 de la Constitución Nacional, que establece que el Estado nacional "sostiene el culto católico" pero no define totalmente de qué tipo debe ser dicho "sostén", en la práctica consistente en el pago de sueldos a los obispos, sacerdotes y estudiantes de seminarios. También había un sector de evangélicos que se oponía radicalmente a la existencia de cualquier tipo de Registro de Cultos, que el anteproyecto mantenía.

Luego de arduas negociaciones, el proyecto Centeno fracasó en virtud de la presión que colocaban tanto los pastores evangélicos más radicales, que querían abolir todos los privilegios de la Iglesia Católica, como los obispos católicos conservadores, que querían mantener todas sus prerrogativas.

Por otra parte, la propia Secretaría de Culto funcionaba como un campo de fuerzas, donde alternativamente ganaban el control los católicos liberales y los católicos conservadores. Estas idas y venidas eran un reflejo de los intercambios entre el Poder Ejecutivo Nacional y el Vaticano, con independencia de los obispos locales que en ocasiones sufrían una operación de "bypass" político. Dentro de la misma Secretaría, a su vez, la oficina del Registro Nacional de Culto ejercía prácticas restrictivas en forma paralela (y en cierto modo contradictoria) a las de la alta conducción de la Secretaría de Culto, gracias a las atribuciones que le confería la ley de facto de 1978. El ajuste de trabas administrativas para obtener registros, o para no perderlo, funcionó como una forma de "control burocrático" (Frigerio y Wynarczyk, 2003) que impidió a las pequeñas iglesias pentecostales y a numerosos templos de umbanda registrarse y así acceder a un status legal ${ }^{14}$. Aunque el derecho a profesar libremente la propia fe está amparado por la Constitución, la no inclusión entre los registrados vuelve a los templos más vulnerables al control policial ante denuncias de cualquier tipo (quejas de los vecinos, requisas en busca de sospechosos, etc.). 


\section{e) Construcción del frente evangélico en la esfera cívica}

A comienzos de la década de los 90 el movimiento religioso evangélico, motorizado por el polo conservador bíblico, había acumulado un importante stock de recursos demográficos, culturales y organizativos, aptos para desarrollar acciones de protesta cívica. En otro orden, los evangélicos habían construido una percepción de su propia identidad como "la iglesia de Cristo", comisionada y empoderada para "conquistar Argentina para Cristo", y sabían que sus filas formaban un porcentaje importante de la población. En el camino experimentaron numerosos logros que fortalecieron sus propias aspiraciones, y las plasmaron en la frase: "Vamos por más". Ese "vamos por más" ahora significaba: "queremos la igualdad de cultos". Las percepciones del contraste entre sus logros, sus expectativas de "ir por más" y las barreras jurídicas que legitimaban un favoritismo institucional católico, la oposición del movimiento anti-sectas y la no suficientemente buena imagen que transmitían los medios de comunicación fueron interpretadas por los pastores como una situación de injusticia que le impedía a la "iglesia de Cristo" cumplir con su cometido. Estos sentimientos eran compatibles con sus ideas teológicas sobre la inminencia de hechos que irían a cambiar en forma radical y dramática la realidad. De protagonistas de un movimiento social religioso pasaron a protagonistas de un movimiento social en sentido estricto que llegaría a ocupar páginas de los diarios principales. Los evangélicos se movilizaron para modificar el entorno jurídico del mercado religioso y mostrar a la sociedad no creyente su efectiva presencia en el país.

A partir de los 90 los evangélicos hicieron varias salidas al espacio público en forma colectiva para protestar por sus derechos. Las más importantes fueron las concentraciones masivas alrededor del Obelisco de Buenos Aires, ambas veces un 15 de septiembre, en 1999 y $2001^{15}$. Los dos eventos se inscribieron en el contexto político marcado por la presencia de la coalición partidaria conocida 
como Alianza, de centro izquierda, presidida por el partido Unión Cívica Radical en el Poder Ejecutivo Nacional (Fernando de la Rúa presidente). En la Secretaría de Culto trabajaba un equipo dirigido por católicos con afinidades a este partido.

Por medio de las convocatorias en el Obelisco de la ciudad los dirigentes evangélicos percibieron su movimiento como una minoría que dejó de ser considerada como tal y comenzaba a ser tomada en cuenta como una fuerza que podría obtener nuevos logros “institucionales, sociales y pastorales”. El espacio de 1999-2001 marcó la cima del proceso de consolidación cohesiva del campo evangélico frente a las restricciones del sistema jurídico, la acción del Estado y los privilegios de la Iglesia Católica. Los activistas del movimiento, todos ellos pastores, hicieron un trabajo de adaptación del marco interpretativo de la acción colectiva, la estrategia, las tácticas y la retórica a las propiedades ambientales del campo de acción y la arena de debate jurídico, sin desconectarse de metas originales que emanaban del movimiento social religioso y las tradiciones salvacionistas del polo conservador bíblico.

El encuadre ambiental cerró con el abrupto abandono de la presidencia de la nación por su titular en diciembre del 2001. Este último evento trajo como consecuencia la profundización de una crisis económica, política y social que afectó extensa y profundamente a la población argentina. Y, con la consecuente toma de poder por el partido Peronista, trajo el reemplazo en la Secretaría de Culto del elenco de católicos aperturistas hacia la diversidad religiosa por católicos dispuestos a mantener y reforzar el control del Estado sobre el mercado religioso - asesorados por uno de los principales activistas anti-sectas. Su postura se basaba en un paradigma esencialista según el cual la relación de la Argentina con Dios se establece por medio de la Iglesia Católica y ésta, con su tradición, define la identidad de la nación, en un curso histórico cuyo comienzo es anterior a la república independiente ${ }^{16}$. 


\section{Conclusiones}

A través del análisis del caso evangélico, hemos intentado mostrar cómo el pasaje de una situación de monopolio a una de pluralismo religioso conlleva una serie de continuidades y que en rigor el crecimiento de la diversidad religiosa no necesariamente implica pluralismo - de acuerdo con nuestras definiciones teóricas expuestas al comienzo de este trabajo. Al contrario, como muestra el pánico por las "sectas" desatado a comienzos de la década de 1990, es posible que el crecimiento de la diversidad lleve a una reacción y al reforzamiento de la regulación social, si no estatal (o a ambas). Para un análisis integral y realista del estado del campo religioso en una supuesta situación de "pluralismo", es necesario tomar en cuenta el grado de regulación del mercado y tomar conciencia de que ésta regulación es multidimensional y excede lo meramente normativo y estatal.

Como muestra el caso analizado, las situaciones de disputa alrededor del grado de regulación del mercado religioso involucran una gama de actores mayor que la que aparece en el modelo dominante basado principalmente en la relación Estado-Iglesia y en la idea de crisis estructural del sistema socioeconómico, anomia, afinidades culturales y disponibilidad de la demanda movilizable frente a la oferta que la incentiva. En esta posición alternativa, es importante comprender el rol del periodismo y los medios, los activistas antisectas, los operadores de la Justicia, el Poder Legislativo y el Poder Ejecutivo.

Desde ellos emanan las tendencias hacia el mantenimiento y refuerzo de la regulación por medio del aparato jurídico del Estado, en favor de la Iglesia Católica y en desmedro de la capacidad de intervención de otras "firmas religiosas" en el mercado. Pero entre ellos asimismo existen actores moderados dispuestos a superar el concepto de "tolerancia" asimétrica, desde el Estado-católico hacia los cultos no católicos, como muestran las iniciativas gestadas 
alrededor del proyecto Centeno. Es necesario tener una visión amplia de la regulación estatal, que exceda lo meramente normativo y abarque aún acciones administrativas de menor rango pero que pueden permitir ejercer, como continúa siendo el caso en el país, un control burocrático delas inscripciones que, junto con la arbitrariedad del accionar de otros representantes estatales, como la policía, puede dificultar o entorpecer la actividad cotidiana de los templos e iglesias. De la misma manera, es preciso avanzar en la comprensión de la regulación social del mercado que, dependiendo del país, puede otorgar relevancia a distintos actores seculares o religiosos. Para el caso argentino, las editoriales de libros, al publicar mayormente obras en contra de "las sectas" - que en un comienzo tuvieron a los evangélicos como protagonistas inequívocos -, o, al editar libros que ensalzan sólo los milagros de la Virgen u otros santos católicos, están inequívocamente formando parte de la maquinaria de control social. Otro tanto se puede decir de los productores locales de series de televisión, que comenzaron a incluir las "sectas" como elementos dramáticos y negativos de sus guiones (Frigerio, 2000b). El rol de los medios de comunicación en general dentro de la creación de un pánico moral sobre las "sectas" queda claro de este trabajo y otros (Frigerio, 1993, Frigerio y Oro, 1998).

Por otro lado, la progresiva desregulación (estatal o social) del mercado no eliminaría por sí sola la situación de favoritismo estatal de la que goza la Iglesia Católica, evidenciada de diversas maneras: por el artículo 2 de la Constitución, que afirma que "el Estado sostiene el culto católico"; por el hecho de que el Derecho Civil promulgue a esta institución una persona de derecho público y por la existencia de otra serie de medidas de distinto grado de normatividad que la tienen como protagonista y beneficiaria.

Aún reconociendo que en situaciones de crecimiento de la diversidad y de pretendido "pluralismo" persisten la regulación multidimensional del mercado religioso y el favoritismo estatal hacia 
una determinada religión, es necesario resaltar también la agencia de las propias organizaciones religiosas. En el caso de las iglesias y federaciones evangélicas que hemos analizado, es evidente que desarrollan una interpretación de su situación frente a la sociedad civil y el Estado y reaccionan a partir de la convicción del valor de su propia fuerza. Desenvuelven tácticas de lobby y acción colectiva en la escena pública, y a la postre ejercen presiones suficientes para despertar la atención de los poderes del Estado, y en particular de la agencia especializada del Poder Ejecutivo: la Secretaría de Culto, así como, finalmente, del periodismo y otros actores sociales.

\section{Notas}

1 Frigerio (2007) argumenta que, ante la ausencia, al menos para el caso latinoamericano, de datos cuantitativos acerca de la situación de las creencias religiosas en el pasado (digamos, de las primeras cinco o seis décadas del siglo XX), la mayor parte de las investigaciones cuantitativas cotejan la situación actual con el pasado supuesto brindado por esta perspectiva teórica. Por lo tanto, los datos empíricos actuales son leídos comparándolos, explícita o implícitamente, con un pasado determinado no por la empiria sino por la teoría, y lo novedoso de la situación actual lo es respecto de un pasado hipotético. Pocos autores han reconocido este problema, que De la Torre $(1999$, p. 130) señala con claridad: “¿Cómo precisar el cambio religioso sin tener claro el antes y el después? ¿lo que hoy en día se aprecia como impacto de la secularización, podría ser una derivación de procesos de larga duración, como, por ejemplo, la religiosidad popular? [...] no contamos con estudios similares que nos permitan comparar el antes y el después en el contexto espacial de Guadalajara, por lo que tan sólo podemos recrear un antes a través de un imaginario del estado de las cosas poco preciso [...]". Para una reseña crítica de este paradigma desarrollado en numerosas publicaciones por Rodney Stark, Laurence Iannaccone y Roger Finke, ver Frigerio (2000a). 
2 El polo conservador bíblico se descompone en dos sectores, evangélico, con predominio de bautistas y hermanos libres, y pentecostal (Wynarczyk, 2003a, 2003b). Dentro del sector pentecostal, por su vez, diferenciamos: (a) pentecostales clásicos, pertenecientes a las grandes redes denominacionales misioneras; (b) pentecostales neoclásicos (Mariano, 1999), surgidos a mediados del siglo XX como separaciones locales de las iglesias clásicas; (c) neopentecostales, surgidos a partir de los 80 en grandes contextos urbanos (Buenos Aires, Río de Janeiro, Bogotá y otros). La taxonomía excluye a la Iglesia Universal del Reino de Dios y la asimila a la categoría de iglesias de "isopentecostalismo", de acuerdo con la clasificación de Bernardo Campos (1997, p. 28).

3 Esta dinámica de aproximaciones y distanciamientos depende, a su vez, de las relaciones del sistema con otros sistemas que constituyen su entorno alrededor de problemas de política y moral sexual y reproductiva (Wynarczyk, 2007).

4 Ambos fenómenos de movilización social colectiva, que tuvieron lugar entre los años 1980 y 2001, fueron exhaustivamente estudiados por medio de técnicas de investigación documental y de campo, y encuadrados en una amplia articulación de dispositivos teóricos, en la tesis doctoral de Wynarczyk (2007). Esta tesis constituye la fuente de la exposición siguiente, que se focalizará solamente en el primero y más relevante de los mencionados procesos de entrada de los conservadores bíblicos en la escena pública de la sociedad civil argentina, la protesta por la "igualdad de cultos". El desarrollo del proceso de formación de partidos políticos evangélicos se encuentra en Wynarczyk, 2006.

5 Distinguimos los procesos de movilización social en sentido lato de los movimientos sociales en sentido estricto, a partir de un elemento crítico para la caracterización de estos últimos: la protesta por la reivindicación de derechos conculcados o sin representación política, frente a una autoridad considerada injusta. El interés analítico que despierta este fenómeno de formación de un movimiento social en stricto sensu a partir de un movimiento social de tipo religioso (movimiento social en sentido lato), constituye el punto de partida de la tesis de Wynarczyk (2007). En efecto, su planteo del problema de investigación se pone en 
línea con la atención que la sociología de la religión ha venido dedicando a la emergencia del protestantismo de raíces conservadoras bíblicas como un movimiento social (Casanova, 1994; Maróstica, 1994, 1997 para la Argentina) y la pregunta sobre "cuándo" los grupos religiosos conservadores se desplazan desde formas de conducta pietista y fuga del mundo hacia modelos de activa participación social que pueden llegar a la formación de partidos políticos (Zald \& McCarthy, 1987, p. 95). Para análisis de la articulación del estudio de movimientos sociales y religiosos ver Frigerio (2003) y Carozzi $(2006,1998)$.

6 Otro ejemplo fueron los embates sufridos por los espiritistas, quienes tuvieron que sobrellevar a la salida de su mayor acto público en 1954 una pelea generalizada con grupos católicos que se oponían a sus ideas.

7 Años más tarde, otros pastores tuvieron menos suerte: en 1967 el predicador norteamericano Morris Cerrullo no pudo llevar a cabo su campaña en la ciudad de Rosario (la segunda más importante del país) por la oposición del Colegio Médico. Sólo pudo hacerlo en 1973 cuando un juez denegó el pedido del Colegio Médico argumentando que el pastor "no provee remedios de ningún tipo, declara enfáticamente su respeto por la ciencia médica y los médicos y sus acciones sólo se basan en el poder de la fe en Dios y en su palabra" (Horvath, 1977, p. 86).

8 Sin embargo, desde 1960, con la llegada del predicador Billy Graham (en esa fase de su carrera un anticomunista en gira por naciones latinoamericanas con Fidel Castro comenzando un ciclo de prestigio y poder), quedaron definitivamente establecidas en el polo conservador bíblico las formas de trabajo propias de la organización racional de campañas, que con el tiempo mejorarían y traerían sus frutos.

9 Según esta ley el registro es obligatorio, pero no otorga personería jurídica. Para ello, luego del registro, las instituciones religiosas deben inscribirse en otras oficinas gubernamentales para obtener el status de entidades legales (asociaciones civiles, entidades de bien público, etc.). Esto implica que deben tener una estructura organizativa paralela que cumpla con los requisitos legales exigidos a las asociaciones civiles. Recién luego de ambos trámites pueden existir como "entidades legales 
privadas", mientras que la Iglesia Católica existe como una "entidad legal pública" en virtud de las leyes del Código Civil Argentino. Esta ley fue reemplazada recién en el 2005 por otra que sí otorga personería jurídica a las instituciones religiosas que se registren.

10 Para los datos cuantitativos de este punto nos basamos en el análisis de Wynarczyk (2007). Para los años 90 se apoya en informaciones de las firmas encuestadoras Graciela Roemers y Asociados y Hugo Haimé, y el censo evangélico conducido por Saracco (1992). Los datos de este último fueron trabajados por Wynarczyk, Semán (1995) y de Majo (1995). Para la década del 2000, se basa en el Informe 2001 del Alto Comisionado para los Derechos del Hombre de las Naciones Unidas (Amor, 2001, p. 4), datos del Departamento de Estado Americano (Estados Unidos, Bureau of Democracy, Human Rights and Labor, 2001), trabajo de campo de Gallup de Argentina para la Conferencia Episcopal Argentina (2002) e informaciones del Consejo Nacional Cristiano Evangélico (CNCE, 2003), construidas mediante reportes estimativos de sus pastores. Lamentablemente, para caracterizar el campo evangélico en términos cuantitativos los datos estadísticos disponibles siguen siendo aproximativos. En buena medida se basan en impresiones, muestras parciales y niveles de calidad técnica dudosa. Las consultoras privadas de opinión pública y encuestas políticas, que en algunos momentos preguntan la filiación religiosa de los encuestados, trabajan con bases estadísticas exiguas en lo referente a los evangélicos, motivo por el cual las proyecciones al universo son poco confiables. Por otra parte, su manejo de la taxonomía del campo evangélico en ciertos casos se revela inadecuada. Los informes de Naciones Unidas y Departamento de Estado no indican sus fuentes, parecieran basarse en informaciones de segunda mano. Dentro de los límites explicados, nuestros conocimientos estadísticos se basan en una estrategia de mosaicos de acuerdo con un criterio metodológicamente aceptado de yuxtaposición de datos disponibles.

11 La concentración de registros de culto en las provincias argentinas, excluida la de Buenos Aires, en ningún caso supera el 5\%.

12 "Preocupación por las sectas", diario Clarín, 20 abr. 1986. 
13 El argumento del lavado de cerebros resultó más eficiente que el anterior porque presentaba virtudes desde el punto de vista de la eficacia: (a) era políticamente correcto merced a la defensa de los niños, los adolescentes, la familia, las madres, la libertad individual y los Derechos Humanos; (b) parecía científico, apelaba a las herramientas conceptuales supuestamente provistas por la psicología; (c) podía producir pánico, enfocaba reportes periodísticos de robos, asesinatos y mutilaciones de niños en contextos para-evangélicos (Los Niños de Dios) y satánicos (Lineamiento Universal Superior), con intervención de la Justicia y la policía; (d) apuntaba a pequeñas agrupaciones marcadamente desviantes ajenas al campo evangélico, que dejaban activar, a través de la instalación mediática del "problema de las sectas" y la gestación de un pánico moral, acciones legislativas capaces de restringir el campo de acción de los evangélicos.

14 Durante la década de 1990, por ejemplo, hubo un promedio de sólo 34 inscripciones por año, en comparación con 209 al año en el lustro 1985-1990. En 1993 y 1994, años subsiguientes al pánico moral sobre sectas, el registro anual fue de 9 y 12, respectivamente (Frigerio y Wynarzcyk, 2003). El ajuste de tuerca burocrático también llevó a muchas agrupaciones a perder el registro que tenían. Antes de 1997, existían 3105 instituciones religiosas registradas; luego de julio del 2000, sólo quedaban 2329, una disminución del 25\%. La magnitud de las cancelaciones se puede apreciar si sabemos que, antes de 1997, sólo 95 registros en total habían sido cancelados. La mayor parte de las bajas se da cuando, en un cambio de Secretarios de Culto, un activista antisectas ingresa como asesor.

15 Intentos anteriores, en 1988 y 1993, para protestar por la ley de cultos en el espacio público y ante el poder legislativo habían sido invisibilizados por los medios pese a contar con una asistencia relevante. El éxito de estas concentraciones y su mayor visibilidad se deben, probablemente, a que la imagen de los evangélicos fue paulatinamente mejorando y sobretodo a que, para 1999, ya llevaba tres años de funcionamiento el Consejo Nacional Evangélico, que nucleaba a las tres principales federaciones. Una masiva concentración convocada por un pastor un año antes había sido opacada por un festival de tango que transcurría 
a su lado. El diario Clarín (13 dic. 1998) tituló: "Una multitud en el Obelisco, por el tango y por una cruzada". El comentario inicial rezaba: "Anoche cerró el Festival de Tango y a pocos metros un pastor evangelista convocó a miles de personas en un acto contra las adicciones. El presidente Fernando de la Rúa estuvo en los dos escenarios”.

16 Los datos empíricos con los cuales trabajamos llegan hasta el año 2001. Los evangélicos organizaron un "tercer obelisco" el 1 de noviembre del 2003, cuyo impacto multitudinario fue modesto. La Secretaría de Culto sufrió otro vuelco a partir del año 2004 con la asunción de la presidencia de Néstor Kirchner, en cuyo análisis no podemos entrar. Apenas podemos señalar desde una perspectiva impresionista que, en esta nueva etapa, no hubo un predominio de los elencos católicos liberales ni conservadores. En tal sentido se produjo un quiebre que merecería un estudio aparte. En este lapso comenzó nuevamente la rueda infructuosa de interacciones para producir una nueva ley de culto. Pero sigue en vigencia (2008), más o menos aplicada, la ley de facto sancionada en 1978 casi al comienzo de la dictadura militar mientras ejerció la presidencia de la nación el general Videla. Mientras tanto la tensión binaria del campo evangélico procesada a lo largo de los dos polos, histórico liberacionista y conservador bíblico, renovó su fuerza a partir de otras influencias contextuales entre los años 2003 y 2007. En este caso, alrededor de los debates sobre salud reproductiva. $\mathrm{Al}$ asumir la presidencia la abogada Cristina Fernández de Kirchner, la Secretaría de Culto muestra el alejamiento de funcionarios que habían adquirido experiencia en el tema religioso, aunque el Secretario de Culto anterior permanece en el cargo.

Diversity is not the same as pluralism: changes in Argentina's religious field (1985-2000) and the evangelicals' fight for their religious rights

Abstract: The paper argues that in order to understand the current state of the Argentine religious field and the development of new religions it is necessary to include the social resistance they encounter into our analysis. It criticizes the widespread idea 
that after the erosion of Catholic monopoly a religious market is effortlessly formed and pluralism simply ensues. Drawing on recent work by James Beckford, it argues that religious diversity does not necessarily entail pluralism (its positive evaluation). Emphasizing the idea central to the religious economies paradigm (Stark, Iannaccone) that the degree of regulation of a religious market is always a crucial variable to consider, it follows Grim and Finke's multidimensional approach to regulation, taking into account governmental as well as social regulation. It exemplifies these ideas by examining the rise of an evangelical social movement - out of a prior merely religious one - that strives for equal religious rights in a situation of supposed religious pluralism in Argentina.

Key words: religion; religious pluralism; evangelicals; Argentina.

\section{Bibliografía}

AMOR, Abdelfattah. 2001. Visite en Argentine (23-30 avr. 2001). Mission du Rapporteur Spécial sur la Liberté de Religion ou de Conviction. Nations Unies. Haut Commissariat Aux Droits de 1'Homme.

BECKFORD, James. Social theory and religion. Cambridge: Cambridge University Press, 2003.

BERGER, Peter. The social reality of religion. Londres: Faber \& Faber, 1969. Versión inglesa de: The sacred canopy.

CAMPOS, Bernardo. De la reforma protestante a la pentecostalidad de la iglesia: debate sobre el pentecostalismo en América Latina. Quito: Consejo Latinoamericano de Iglesias, 1997.

CAROZZI, María Julia. El concepto de marco interpretativo en el estudio de movimientos religiosos. Sociedad y Religión, Buenos Aires, n. 16/17, p. 33-52, 1998.

- Otras religiones, otras políticas: algunas relaciones entre movimientos sociales y religiones sin organización central. Ciencias Sociales y Religión / Ciências Sociais e Religião, Porto Alegre, 8, p. 11-29, 2006. 
CASANOVA, José. Public religions in the modern world. Chicago: University of Chicago Press, 1994.

DA COSTA, Néstor. Religión y sociedad en el Uruguay del siglo XXI. Montevideo: Centro Latinoamericano de Economía Humana (Claeh), 2003.

DE LA TORRE, Renée. El catolicismo: ¿un templo en el que habitan muchos dioses? En: FORTUNY, Patricia (Comp.). Creyentes y creencias en Guadalajara. México: Consejo Nacional de la Cultura y las Artes (Conaculta), 1999, p. 101-131.

ESQUIVEL, Juan Fabián García; HADIDA, María; HOUDIN, Victor. Creencias y religiones en el Gran Buenos Aires: el caso de Quilmes. Buenos Aires: Universidad Nacional de Quilmes, 2001.

ESTADOS UNIDOS. Bureau of Democracy, Human Rights, and Labor. Libertad religiosa en Argentina. En: Informe 2001 (octubre) sobre la libertad religiosa en los países. Tomado del sitio: <http://www. state.gov/g/drl/rls/irf/2001/5537.htm>.

FORTUNY, Patricia (Comp.). Creyentes y creencias en Guadalajara. México: Centro de Investigaciones y Estudios Superiores en Antropología Social (Ciesas): Instituto Nacional de Antropología e Historia (Inah), 1999.

FRIGERIO, Alejandro. La invasión de las sectas: el debate sobre nuevos movimientos religiosos en los medios de comunicación en Argentina. Sociedad y Religión, Buenos Aires, 10, p. 24-51, 1993.

- ¿No será una secta?: imágenes de problemas sociales en programas televisivos de ficción. Cuadernos de Antropología Social, Buenos Aires, 11, p. 387-404, 2000b.

Outside the nation, outside the diaspora: accomodating race and religion in Argentina. Sociology of Religion, Galva, IL, 63(3), p. 291-315, 2002.

- ¡Por nuestros derechos ahora o nunca!: construyendo una identidad colectiva umbandista en Argentina. Civitas Revista de Ciências Sociais, Porto Alegre, 3(1), p. 35-68, 2003. 
FRIGERIO, Alejandro. Repensando el monopolio religioso del catolicismo en la Argentina. En: CAROZZI, María Julia; CERIANI, César. Ciencias sociales y religión en América Latina. Buenos Aires: Biblos: Asociación de Cientistas Sociales de la Religión del Mercosur (ACSRM), p. 87-118, 2007.

- Teorias econômicas aplicadas ao estudo da religião: em direção a um novo paradigma?. Revista Brasileira de Informação Bibliográfica em Ciências Sociais (BIB), Rio de Janeiro, 50, p. 125144, 2000a.

; ORO, Ari. Sectas satánicas en el Mercosur: un estudio de la construcción de la desviación religiosa en los medios de comunicación de Argentina y Brasil. Horizontes Antropológicos, Porto Alegre, 8, p. 114-150, 1998.

; WYNARCZYK, Hilario. Cult controversies and government control of new religious movements in Argentina. En: RICHARDSON, James. Regulating religion: case studies from around the globe. New York: Kluwer Academic: Plenum Publishers, 2003, p. 453-475.

GIMÉNEZ BELIVEAU, Verónica; ESQUIVEL, Juan. Las creencias en los barrios o un rastreo de las identidades religiosas en los sectores populares urbanos del Gran Buenos Aires. Sociedad y Religión, Buenos Aires, 14/15, p. 117-128, 1996.

GRIM, Brian; FINKE, Roger. International Religion Indexes: government regulation, government favoritism, and social regulation of religion. Interdisciplinary Journal of Research on Religion, 2, art. 1, 2006. Available at: $<$ http://www.religjournal.com $>$.

HERVIEU-LÉGER, Danièle. Secularization and religious modernity in Western Europe. En: SHUPE, Anson; MISZTAL, Bronislaw. Religion, mobilization and social action. Westport, CT: Praeger, 1998, p. 15-31.

HORVATH, Ricardo. Los manosantas. Buenos Aires: Todo es Historia, 1977. 
LUCKMANN, Thomas. The invisible religion. Londres: McMillan, 1967.

MALLIMACI, Fortunato. Prólogo. En: ESQUIVEL, Juan Fabián García; HADIDA, María; HOUDIN, Victor. Creencias y religiones en el Gran Buenos Aires: el caso de Quilmes. Buenos Aires: Universidad Nacional de Quilmes, 2001, p. 13-31.

MARIANO, Ricardo. Neopentecostais: sociologia do novo pentecostalismo no Brasil. São Paulo: Loyola, 1999.

MARÓSTICA, Mathew. La iglesia evangélica como nuevo movimiento social. Sociedad y Religión, Buenos Aires, 12, p. 3-17, 1994a.

. Pentecostals and politics: the creation of the Evangelical Christian Movement in Argentina, 1983-1993. 1997. Ph.D. dissertation (in Political Science) - Political Sciences Department, University of California, Berkeley, United States.

SARACCO, J. Norberto. Argentine Pentecostalism: its history and theology. 1989. Tesis (Doctorado en Teología) - University of Birmingham, Birmingham, England.

(Ed.). Directorio y censo de iglesias evangélicas de la ciudad de Buenos Aires. Buenos Aires: Facultad Internacional de Estudios Teológicos (Fiet): Logos, 1992.

SECRETARÍA NACIONAL DE CULTO. Digesto de Derecho Eclesiástico Argentino. Buenos Aires: Ministerio de Relaciones Exteriores, Comercio Internacional y Culto, 2001.

STARK, Rodney; IANNACCONE, Laurence. Rational choice propositions about religious movements. Religion and the Social Order, Greenwich, CT, 3A, p. 241-261, 1993.

WYNARCZYK, Hilario. Ciudadanos de dos mundos: la entrada de los evangélicos conservadores a la vida pública desde los 80 en la Argentina. 2007. Tesis (Doctorado en Sociología) - Universidad Católica Argentina, Buenos Aires.

. Entre el legado y los desafíos: las iglesias evangélicas en la Argentina. En: CHIQUETE, Daniel; ORELLANA, Luis. Voces 
del pentecostalismo latinoamericano. Concepción (Chile): Red Latinoamericana de Estudios Pentecostales, 2003a.

WYNARCZYK, Hilario. La guerra a los demonios y la economía espiritual del cosmos. En: PINKLER, Leandro. La religión en la época de la muerte de Dios. Buenos Aires: Marea, 2005, p. 167-178.

. Los evangélicos en la sociedad argentina, la libertad de cultos y la igualdad: dilemas de una modernidad tardía. En: BOSCA, Roberto. La libertad religiosa en la Argentina: aportes para una legislación. Buenos Aires: Calir: Konrad Adenauer Stiftung, 2003b, p. $135-158$.

. Partidos políticos evangélicos conservadores bíblicos en la Argentina: formación y ocaso 1991-2001. Civitas Revista de Ciências Sociais, Porto Alegre, 6(2), p. 11-42, 2006.

; JOHNS, Robert. "Estudio de campo en los barrios de Palermo y Belgrano sobre distribución de pertenencias religiosas, muestra de 395 casos". Informe de consultoría, no publicado, 1996.

; SEMÁN, Pablo; DE MAJO, Mercedes. Panorama actual del campo evangélico en Argentina. Buenos Aires: Facultad Internacional de Estudios Teológicos (Fiet), 1995. Tomado del sitio: $<$ http://www.prolades.com $>$.

ZALD, Myer; McCARTHY, John. Religious groups as crucibles of social movements. In: Social movements in an organizational society. Edison, NJ: Transaction Publishers, 1987. 